\title{
Acute gastroenteritis, video camera and cruise ship
}

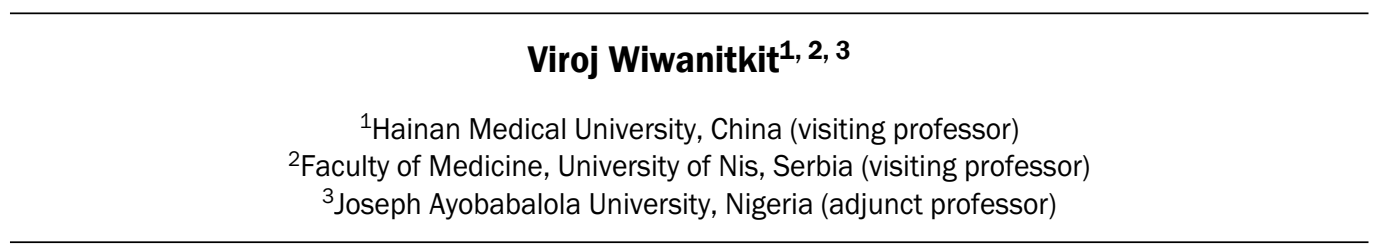

Sir, the recent report on acute gastroenteritis, video camera and cruise ship is very interesting [1]. Diskin et al. [1] discussed on the use of "surveillance video cameras" as a possible mean to manage the problem. At present, the gastroenteritis on cruise ships becomes a new concern in travel medicine due to increased prevalence [2]. In fact, the port control of the immigrant with infectious disease is usually a difficult thing. The problem can be the same as the problem identified at airports. The short observation by any tool might contribute to detection of the infectious disease. Controlling the problem during the cruise seems to be difficult and the control of infection during the cruise is sometimes unsuccessful. Adopting improved sanitation practices during the cruise can be a good preventive me- thod [3]. The additional process such as mandatory health certification might also be useful. However, this might cause a problem with the privacy of cruise passengers.

\section{REFERENCES}

1. Diskin AL, Caro GM, Dahl E. Acute gastroenteritis and video camera surveillance: a cruise ship case report. Int Marit Health 2014; 65: 20-22.

2. Cramer EH, Blanton CJ, Blanton LH, Vaughan GH Jr, Bopp CA, Forney DL. Vessel Sanitation Program Environmental Health Inspection Team. Epidemiology of gastroenteritis on cruise ships, 2001-2004. Am J Prev Med 2006; 30: 252-257.

3. Carling PC, Bruno-Murtha LA, Griffiths JK. Cruise ship environmental hygiene and the risk of norovirus infection outbreaks: an objective assessment of 56 vessels over 3 years. Clin Infect Dis 2009; 49: 1312-1317. 